\title{
Modeling the influence of delamination on the mechanical performance of straight glued laminated timber beams
}

\author{
Florindo Gaspar ${ }^{\mathrm{a}, *}$, Helena Cruz ${ }^{\mathrm{b}}$, Augusto Gomes ${ }^{\mathrm{c}}$ \\ a Polytechnic Institute of Leiria, School of Technology and Management, Morro do Lena, Alto do Vieiro, 2411-901 Leiria, Portugal \\ ${ }^{\mathrm{b}}$ Structures Behaviour Division, Laboratório Nacional de Engenharia Civil, Av. do Brasil, 101, P-1700-066 Lisboa, Portugal \\ ${ }^{c}$ University of Lisbon, IST, Department of Civil Engineering, Av. Rovisco Pais, 1049-001 Lisboa, Portugal
}

\section{H I G H L I G H T S}

- Finite element modeling was used to evaluate straight glued laminated timber beams.

- Non-symmetric delamination can cause the member's lateral instability.

- Symmetric delamination on low shear stress areas is not a problem.

- High delamination can be achieved without reach the elastic limit.

- Structural integrity may be at risk for delamination depth higher than $60 \%$.

\section{A R T I C L E I N F O}

Article history:

Received 20 February 2015

Received in revised form 21 July 2015

Accepted 4 August 2015

\section{Keywords:}

Glued laminated timber

Delamination

Finite element models

\begin{abstract}
A B S T R A C T
Delamination at the glue lines is a key factor to take into account when assessing glued laminated timber members in service. In order to gain a more objective and wide knowledge about the importance of delamination in relation to its type and extension, a numerical study was developed.

Finite element modeling (FEM) was used to evaluate the influence of delamination - near the surface, on the vertical faces and ends - on the mechanic performance of straight glued laminated timber beams. The FEM was validated by comparing stresses and deformations obtained with the model and with the application of the beam theory, showing satisfactory results. Results show that when delamination is non-symmetric regarding the member's cross section, it can cause the member's lateral instability, thus increasing its stresses and deformations. Delamination is not a problem when it occurs in members or member areas with low shear stresses, particularly when it is symmetric and does not reach the whole width of the beam. The stresses corresponding to the bending or deformation limit-states get near the elastic limit only for very important delamination. Moreover, delamination depth higher than $60 \%$ of the cross section width may be regarded as a turn point beyond which the structural integrity may be at risk.
\end{abstract}

(c) 2015 Elsevier Ltd. All rights reserved.

\section{Introduction}

Delamination at the glue lines is a key factor to take into account when assessing glued laminated timber members in service. Not only delamination enables water intake in exterior structures fully exposed to weather and thus progressive damage due to moisture induced dimensional variations [1], but they may denote insufficient strength or durability of the glued joints regarding the service class they are exposed to.

* Corresponding author.

E-mail addresses: florindo.gaspar@ipleiria.pt (F. Gaspar), helenacruz@lnec.pt (H. Cruz), augusto.gomes@tecnico.ulisboa.pt (A. Gomes).
In some cases, local separation of lamellas that are visible at the member faces may result from fabrication defects like adhesive starvation, variations in lamellas' thickness, lack of pressure or a too long open time leading to poor contact or improper adhesion. These are not true delamination of the glued lines and should be the object of complementary tests to check if these glued line openings are just local defects or, on the contrary, adhesion between lamellas may be globally deficient.

A different situation is delamination (the bondline failure in service), that tends to develop as a consequence of stresses resulting from the applied loads or moisture content variations.

Delamination influence on strength and stiffness will depend on their length, depth and exact location in the glulam member, as 
well as on the member size, shape and stress distribution. Particularly worrying is fresh fast-growing delamination, that often indicates a member failure in progress.

In order to gain a more objective and systematic insight on the importance of delamination relative to their type and extension, a numerical study was developed.

The main goal of numerical modeling performed was to assess the impact of delamination in the bearing capacity of the element, in order to make an approach to the problems that the separation of bonded lamellas in service can create in glued laminated timber structures, identifying situations that may justify a more detailed analysis of their safety and suitable remedial measures.

This numerical work focused the case of straight glued laminated timber beams previously tested by the authors for strength and stiffness [2], and therefore results are related to the chosen beam geometry. However, not only the outcome of this study helps understanding the importance of the addressed delamination problem, but it may also contribute to discussing the importance of drying fissures, both in glued laminated timber and solid timber members.

\subsection{Failure of glued joints}

The failure of the glued joints may occur in three distinct modes, in the direction perpendicular to the joint plane (mode I) and the others in the two perpendicular directions contained in the joint plane, mode II (in the longitudinal direction) or mode III (in the direction perpendicular to mode II).

The intensity of stresses or energy required to failure depends of the properties of wood, adhesive and stress state. The presence of small glued joint defects, such as voids, micro-cracks, areas with poor curing of the adhesive or others may generate critical discontinuities in the stress field which could also lead to failure [3]. Serrano and Gustafsson [4] showed that a single, small glueline void can have a considerable influence on reducing finger-joints' strength.

In the analysis of glued joints' failure it is necessary to consider its strength, energy required to failure and shape of the stressstrain curve of the timber. However, for sufficiently large joints it can be assumed that the failure energy is a decisive factor for strength [5]. Results obtained experimentally with common adhesives show that the shear deformation of glued joints is very low in the elastic region, subsequently verifying a high deformation until reaching the failure [6].

For wood, energy is approximately between 200 and $400 \mathrm{~J} / \mathrm{m}^{2}$ for the failure mode I and reaches approximately three times this value for the failure mode II. To make a more accurate assessment, the value of energy corresponding to the mixed mode involving the two previous should be known [7]. The determination of failure energy of glued joints is difficult [8]. For resorcinol/formaldehyde adhesive, Wernersson [5] obtained $360 \mathrm{~J} / \mathrm{m}^{2}$ for the failure energy for mode I and values between 850 and $1000 \mathrm{~J} / \mathrm{m}^{2}$ for the failure energy in mode II. According to the same author, the relationship between the strength $\left(P_{\max }\right)$ and the fracture energy $\left(G_{f I I}\right)$ is as follows:

$P_{\max }=\frac{1}{2} \sqrt{E G_{f I I} b_{n} A}$

where:

$E$ is the modulus of elasticity in bending of wood.

$b_{n}$ is the width of the glued joint.

$A$ is the cross-section of the lamellae.

Petersson [9] developed an expression to determine the critical moment $\left(M_{c}\right)$ where an unstable crack will develop in the glue line between the failed lamination and the rest of the beam:
$M_{c}=\sqrt{\frac{2 G_{f} b E_{L} I}{1 / \alpha^{3}-1}}$

where:

$E_{L}$ is the modulus of elasticity in the direction of the fibers.

$G_{f}$ is the energy needed to propagate a crack.

$b$ is the width of the beam.

$I$ is the moment of inertia of the beam.

$\alpha$ is equal to $(h-\Delta h) / h$ where $h$ is the height of the cross sec-

tion and $\Delta h$ the thickness of the lamella.

In fact, the failure cracks may represent an area of lower strength located at the outermost fibers, such as a knot or a finger-joint, which can fist reach the failure. The subsequent behavior of the beam shall be governed by crack propagation along the beam. This expression leads to the conclusion that the flexural strength decreases with increasing thickness of the lamella. The applicability of this expression was confirmed by Serrano and Larsen [7] that carried out simulations using 2D finite element to model an element with $1.60 \mathrm{~m}$ length subject to bending where a fissure was introduced in the outermost fiber subjected to tension. Furthermore, these authors concluded that with decreasing lamella thickness the governing failure mode changes from mode I to mode II approach, meaning that thinner lamellas (around $3 \mathrm{~mm}$ ) tend to lead to shear failure whereas the failure for ticker lamellas (around $0.05 \mathrm{~m}$ ) tends to be mixed. The possibility of failure beginning in a knot, finger-joint or fissure located in the outermost lamella depends of the height of the beam [10], however this weak zone should always be carefully inspected because it can lead to substantial strength reducing.

\subsection{Influence of delamination or drying cracks}

There are relatively few known studies regarding the influence of delamination or drying cracks on the mechanical performance of glued laminated beams.

Soltis and Gerhardt [11] performed a state of the art review of shear design of wood beams. They mentioned that shear strength depend on crack depth for depth over $30 \%$ of beam width.

Khorasan [12] studied the influence of formed cracks on glulam beams load-carrying capacity. Simulations produced with ABAQUS were compared with previous available experimental results by Anderson and Oden [13]. Two groups of spruce glulam beams of $2.6 \mathrm{~m} \times 0.315 \mathrm{~m} \times 0.115 \mathrm{~m}$ were tested in 3-point bending over a $2.275 \mathrm{~m}$ span. The first group had no cracks and the other had natural cracks due to natural weathering. Although both groups showed similar density, there was no effect of surface cracking on the ultimate strength.

The FEM developed by these authors and calibrated with good approach for these beams was then extended to predict the performance of beams with $9 \mathrm{~m} \times 0.14 \mathrm{~m} \times 0.45 \mathrm{~m}$ that had been exposed to outdoor climate during 5 years. Calibration of the model was done for a beam with a large number of cracks (12 of which over $15 \%$ of the beam width (in this case, between 22 and $44 \mathrm{~mm}$ deep)), distributed along its length but on one face. Simulations were done considering the load point located at midspan, $1 / 4$ or $1 / 8$ of the span, indicating that the strength of the beam is reduced of $5.9 \%, 11.7 \%$ and $26 \%$, respectively.

Pousette and Ekevad [14] studied the importance of different types of cracks for the shear strength of spruce glulam beams. Five types of $2.6 \mathrm{~m} \times 0.115 \mathrm{~m} \times 0.315 \mathrm{~m}$ glulam beams, with or without lengthwise cracks of different depths and locations were tested in three-point bending. Cracks made by sawing (grooves), as well as natural cracks due to weathering, were considered. They tested the following situations: no cracks; one crack in the middle glued 
line, on one face only $30 \%$ of beam width; cracks in the middle glued line, on both faces each of them $15 \%$ of beam width; two cracks on one face, each of them $30 \%$ of beam width. Beams without cracks failed mostly in bending. Although beams with natural drying cracks failed mostly in shear, their characteristic shear strength was about the same as for beams without cracks. Beams with sawn grooves got lower characteristic shear failures, what was attributed to result from the cross section reduction.

Berg et al. [15] investigated the load-bearing capacity of cracked glulam beams. Three-point bending tests were performed on glulam beams of different sizes with pre-manufactured cracks. Experimental results were compared with a numerical model to predict the failure load of the beams due to the cracks. Calibration and validation of experimental tests involved six glulam beams of $5 \mathrm{~m} \times 0.115 \mathrm{~m} \times 0.63 \mathrm{~m}$ with the load applied $1.2 \mathrm{~m}$ from one end of the beam and six glulam beams of $9 \mathrm{~m} \times 0.115 \mathrm{~m} \times 0.63 \mathrm{~m}$, with the load applied $1.125 \mathrm{~m}$ from one end. Two different preproduced crack configurations were used, a $1 \mathrm{~m}$ long crack, $2.5 \mathrm{~mm}$ thick, was cut with a circular saw, starting $0.3 \mathrm{~m}$ from the edge. The crack was sawn (from both sides) to a depth of $30 \%$ of the total thickness. Different locations of the crack were considered. Results showed that a crack in the center of the beams reduced the load-bearing capacity of $70-80 \%$ of that of an uncracked beam. Cracks higher up in the beam decreased the load-bearing capacity to $90 \%$ of that of the reference beam. The $9 \mathrm{~m}$ beam with several cracks had a load-bearing capacity of $70 \%$, which was not much lower than that of a beam with one central crack. In comparison with $40 \%$ of full width there is an increase in load capacity of about $200 \%$. This indicates that the shear strength is not the limiting factor regarding the load capacity.

Published work covers mainly the shear strength of glulam beams and focus specific individual beam geometry and loading conditions (under 3-point bending). Furthermore, a small number of delamination cases is generally considered. A more general overview of the influence of delamination is therefore intended.

\section{Model}

\subsection{Geometry}

A 3-D finite element model of a straight glulam beam was developed using software Abaqus/CAE Version 6.7-EFI of Dassault Systèmes Simulia Corp., Providence, RI, USA.

The modeled beam was $0.10 \mathrm{~m}$ wide $\times 0.24 \mathrm{~m}$ high $(\mathrm{h})$ $(6 \times 0.04 \mathrm{~m}$ thick lamellas $) \times 4.40 \mathrm{~m}$ long, simply supported over a $4.32 \mathrm{~m}$ span (equal to 18 times its height, according to EN 408), with two loads symmetrically applied relatively to the middle of the beam. Tridimensional solid elements of 20 nodes and 3 degrees of freedom per node (displacement in $x, y$ and $z$ directions) were adopted.

Timber lamellas were modeled with elements of $0.04 \mathrm{~m} \times 0.04 \mathrm{~m}$ (the lamellas' thickness) $\times 0.033 \mathrm{~m}$, in the $x, y$ and $z$ directions, respectively. Smaller elements ( $0.02 \mathrm{~m}$ side) had been tried, but although increasing substantially the calculation time, no benefits were obtained.

The adhesive elements were $0.01 \mathrm{~m} \times 0.01 \mathrm{~m}$ (in the glue line plane) $\times 0.1 \times 10^{-3} \mathrm{~m}$ thick ( $x, y$ and $z$ directions, respectively). Delamination was therefore modeled by removing some adhesive elements, and by introducing restrictions at the corresponding interfaces to avoid overlapping.

Supports were modeled to simulate the use of steel plates $(0.08 \mathrm{~m} \times 0.10 \mathrm{~m} \times 0.02 \mathrm{~m}$, in $x, y$ and $z$ directions, respectively) to avoid stress concentration. Similarly, low stiffness material plates of $0.08 \mathrm{~m} \times 0.10 \mathrm{~m}$ were modeled under the loading points.
Displacements were fully restrained at one support and allowed only in the $x$ direction at the other support.

Glued joints were numbered from 1 to 5 , starting from the lower face of the beam.

\subsection{Loading}

The following limit states were considered: deformation (DLS), bending strength (BLS) and shear strength (SLS), according to EN 1995-1-1 [16]. It was considered the service class 2 with permanent and medium-term loads, contributing $75 \%$ and $25 \%$ for the total load, respectively, corresponding to a loading situation common in a roof. The maximum design load for each limit state was determined assuming glulam class GL24h [17], which mechanical properties are presented in Table 1.

For the deformation limit state, the acceptance limits for the instantaneous and final deflections were considered to be equal to $1 / 400$ and $1 / 200$ of the span, respectively. Lateral torsional stability and compression perpendicular to the grain at the supports were also verified.

The deformation and bending limit states were attained for $5 \mathrm{kN}$ and $7.5 \mathrm{kN}$ loads, respectively, applied at $1.44 \mathrm{~m}(6 \times h)$ from the beam ends (the test set up proposed by EN 408 [18]). The shear limit state was attained for $18.4 \mathrm{kN}$ loads applied at a distance of $2 \times h$ from the supports (Fig. 1).

\subsection{Materials}

Since 3-D FEM was considered, the timber was modeled as orthotropic material, to better reproduce the real performance of the beam. So, in addition to the mean modulus of elasticity in the grain direction $\left(E_{0, \text { mean }}\right)$, the modulus of elasticity perpendicular to grain ( $\left.E_{90 \text {,mean }}\right)$, the shear moduli $\left(G_{\mathrm{LR}}, G_{\mathrm{LT}}\right.$ and $\left.G_{\mathrm{RT}}\right)$ and the Poisson coefficients $\left(v_{\mathrm{RL}}, v_{\mathrm{TL}}, v_{\mathrm{LR}}, v_{\mathrm{LT}}, v_{\mathrm{RT}}\right.$ and $\left.v_{\mathrm{TR}}\right)$ had to be considered.

Given the large range of values found in the literature for the modulus of elasticity perpendicular to grain [19-21] and the sensitivity analysis performed by the authors that showed a small variation in predicted results due to variation of the modulus of elasticity perpendicular to grain, the value proposed by EN 1194 [17] was adopted $\left(E_{90 \text {,mean }}=E_{0, \text { mean }} / 30\right)$.

Shear moduli $G_{\mathrm{LR}}$ and $G_{\mathrm{LT}}$ were taken equal to $E_{0 \text {,mean }} \times 6.5 \%$ [17], similar to the value proposed by Bodig and Jayne [19] and $G_{\mathrm{RT}}$ was taken equal to $E_{0 \text {,mean }} \times 0.7 \%$ (the value proposed by Bodig and Jayne [19]).

Values of 0.035 were adopted for Poisson coefficients $v_{\mathrm{RL}}$ and $v_{\mathrm{TL}}$, whereas $v_{\mathrm{LR}}, v_{\mathrm{LT}}, v_{\mathrm{RT}}$ and $v_{\mathrm{TR}}$ were taken equal to 0.4 , based in the work done by Bodig and Jayne [19]. Sensitivity analyses showed however that predictions were not much influenced by Poisson coefficients adopted.

Besides the factors that can be said to define the glued line strength, like the adhesive, wood species, gluing process and bond line thickness, other factors can influence their mechanical properties, as the temperature [22], moisture before and after gluing [23] and load duration [24]. However, it was found from preliminary

Table 1

Mechanical properties adopted for the glued laminated timber $\left(\mathrm{N} / \mathrm{mm}^{2}\right)$.

$\begin{array}{lll}\text { Bending } & f_{m, k}=26.4 & f_{m, d}=16.8 \\ \text { Tension } & f_{t, 0, k}=18.2 & f_{t, 0, d}=11.6 \\ & f_{t, 90, k}=0.40 & f_{t, 90, d}=0.26 \\ \text { Compression } & f_{c, 0, k}=24.0 & f_{c, 0, d}=15.4 \\ & f_{c, 90, k}=2.70 & f_{c, 90, d}=1.73 \\ \text { Shear } & f_{v, k}=2.70 & f_{v, d}=1.73 \\ \text { Modulus of elasticity } & E_{0, \text { mean }}=11,600 & \\ & E_{0,05}=9,400 & \end{array}$



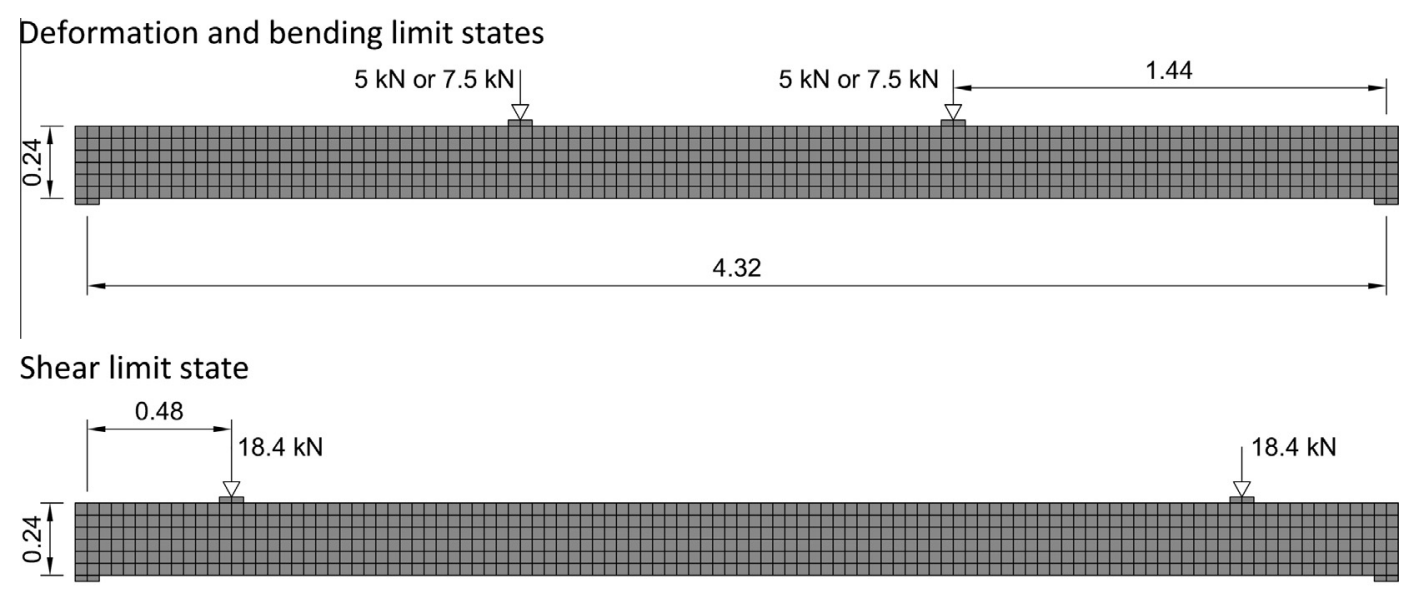

Dimensions in $\mathrm{m}$

Fig. 1. Loading setup.

simulations done by the authors that the values adopted for the mechanical properties of glue line elements would not significantly affect the predicted stresses and deformations, coming in line with the widely accepted minimal influence of glue lines quality in the elastic performance of the beams [19]. Therefore, the same mechanical properties of timber were also adopted for the glue lines.

Since the main issue addressed in this study was the influence of geometry (location and magnitude) of delamination, material properties variation and local weakness due to knots or finger joints were not considered.

Timber was modeled as linear elastic. Besides, plastic behavior was outside the scope of this work. However, in some computer simulations the characteristic strength values were exceeded, compromising safety, so a failure criteria was used in this study. The anisotropic failure criteria of Hill [25], Hoffman [26], Tsai and $\mathrm{Wu}$ [27] and Cowin [28] are often used for wood [29]. Some authors compared different failure criteria applied to wood. Although Mascia and Simoni [30] obtained similar results for Tsai-Hill, Tsai-Wu and Hoffman curves, the prediction of failure depends of the stress state [31] and the high variability of wood mechanical properties and unknown correlation between strength tensor components are limitations [32]. In addition, the choice should be taken according to the computational complexity and the necessities in the failure identification [33]. Given that, in this work, the use of failure criterion was not for calibration purpose, the choice of criterion was not of major importance. The Hill's criterion [25] was chosen (Eq. (3)), in order to compare the stress states obtained in the three limit states' verifications and to identify possible risk situations for the structural member.

$$
\begin{aligned}
& F\left(\sigma_{y}-\sigma_{z}\right)^{2}+G\left(\sigma_{z}-\sigma_{x}\right)^{2}+H\left(\sigma_{y}-\sigma_{z}\right)^{2}+2 L\left(\tau_{y z}\right)^{2} \\
& \quad+2 M\left(\tau_{z x}\right)^{2}+2 N\left(\tau_{x y}\right)^{2}=1
\end{aligned}
$$

where $\sigma_{i}$ and $\tau_{i j}$ represent the normal and shear stresses, respectively, and parameters $F, G, H, L, M$ e $N$ are the mechanical material properties (Eqs. (4)-(9)).

$$
\begin{aligned}
& F=\frac{1}{2}\left[\frac{1}{\left(f_{y}\right)^{2}}+\frac{1}{\left(f_{z}\right)^{2}}-\frac{1}{\left(f_{x}\right)^{2}}\right] \\
& G=\frac{1}{2}\left[\frac{1}{\left(f_{z}\right)^{2}}+\frac{1}{\left(f_{x}\right)^{2}}-\frac{1}{\left(f_{y}\right)^{2}}\right]
\end{aligned}
$$

$$
\begin{aligned}
& H=\frac{1}{2}\left[\frac{1}{\left(f_{x}\right)^{2}}+\frac{1}{\left(f_{y}\right)^{2}}-\frac{1}{\left(f_{z}\right)^{2}}\right] \\
& L=\frac{1}{2\left(f_{y z}\right)^{2}} \\
& M=\frac{1}{2\left(f_{z x}\right)^{2}} \\
& N=\frac{1}{2\left(f_{x y}\right)^{2}}
\end{aligned}
$$

where $f_{x}, f_{y}$ and $f_{z}$, are the strength values of the material along $x, y$ and $z$ axis, respectively and $f_{x y}, f_{y z}$ and $f_{z x}$ are the shear strengths along the $x-y, y-z, z-x$ planes, respectively.

\subsection{Finite element model}

The FEM was validated by comparing stresses and deformations so obtained with the results of applying the beam theory assuming that cross sections would remain plane, for the above referred limit states. Results were satisfactory. As expected, better agreement between FEM and beam theory was obtained when timber isotropic behavior was assumed than with the orthotropic behavior.

The above finite element model was used to evaluate the delamination influence on the mechanical performance of the beam. To do so, the finite elements of the glued joint were removed from the areas where the delamination was simulated. In such areas an interaction was inserted to simulate the contact of the lamellas and avoid overlapping. No lateral restriction was introduced along the length of the beam.

The delamination cases considered had the objective of analyzing the performance of beams in the presence of delamination visible on their vertical faces and ends. The delamination near the surface is a very frequent situation observed in structures in service and is always a reason for concern, because it indicates the existence of degradation and also because it may rise doubts about the integrity of the structural element. The delamination at the ends represents a particular risk to the glued laminated timber structures, not only because they affect cross sections with high shear stresses but also because permeability of wood is higher in the longitudinal direction and water intake at beam ends is likely to create high moisture induced stresses and propagation of delamination. Five delamination modes were simulated: A, B, C, 
D and E (Fig. 2), in order to replicate typical delamination observed in practice. Modes A to D simulate delamination near the surface, although mode E simulates delamination at the beam ends. Delamination influence was checked as a function of its depth, considering both symmetric delamination (modes A,S to E,S) and nonsymmetric delamination (modes B,ns to D,ns). In symmetric modes, delamination varied from 10 to $40 \mathrm{~mm}$ deep (at each face) or up to $40 \mathrm{~mm}$ at one face plus $50 \mathrm{~mm}$ at the other face, in the case of $90 \mathrm{~mm}$ delamination. In non-symmetric modes, delamination was assumed on one face only, varying from 20 to $90 \mathrm{~mm}$. The following delamination modes were considered:

- Modes A and B - delamination along the whole beam length: either just on the middle glue line (mode $A$ ) or in all glue lines (mode B);

- Modes $C$ and D - delamination in all glue lines: either just in a central zone $3.44 \mathrm{~m}$ long (mode $\mathrm{C}$ ) or near the beam ends in 0.48 m length (mode D);

- Mode E - delamination on both ends of the beam and in all glue lines. Delamination length varied from 80 to $480 \mathrm{~mm}$ near each end, affecting the whole beam width. Therefore, in this mode only, delamination 'depth' is measured from the end of the beam, not from the surface.

\section{Results and discussion}

The study of the delamination influence on deformations and stresses was done for the loads corresponding to the three limit states referred above. For deformation limit state, analysis included modes A,s,d to E,s,d for symmetric delamination and B, ns,d to D,ns,d for non symmetric delamination. For bending strength limit state, analysis included modes A,s,b to E,s,b for symmetric delamination and B,ns,b to D,ns,b for non symmetric delamination. For shear strength limit state, analysis covered modes A,s,s to E,s,s for symmetric delamination and B,ns,s to D,ns,s for non symmetric delamination. The following sections present and discuss the obtained results. Figs. 3-9 present the maximum values of deformations, stresses and Hill's criterion for each case, where delamination depth is expressed as a percentage of the maximum delamination depth defined in Fig. 2 (90 mm for modes A to D; $480 \mathrm{~mm}$ for mode E). Design and characteristic stresses were obtained as described above.

\subsection{Influence of non symmetric delamination}

In general, non symmetric delamination is the most unfavourable for the beam performance. Compared to symmetric situations (B,s,d, C,s,d and D,s,d), non symmetric modes (B,ns,d, C,ns,d and D, $\mathrm{ns}$,d) produce larger deformation on the $y$ direction (Fig. 3a). This effect is also shown on modes A,s,d, B,s,d, C,s,d and D,s,d for $90 \mathrm{~mm}$ delamination (100\% delamination depth), which are indeed non symmetric, where a higher increase of deformation is observed. In fact, non symmetric delamination causes the lateral instability of the beam as a result of the non uniform distribution of stresses through the beam. This situation is also shown by deformations in $z$ direction (Fig. 3b). The lateral instability of the beam for non symmetric situations produces larger deformations in $y$ direction for higher delamination, as it is observed in Fig. 3a, comparing modes B,ns,d and C,ns,d.

In the shear strength limit state (SLS - Fig. 4) the results show that the impact of the delamination on the mechanical performance depends of location of the loads, because mode C,ns,s is not significantly worsened due to delamination located out of the "transition" zone between loads and supports, causing a negligible lateral instability in this mode. This was also observed in tension and compression stresses ( $x$ and $y$ directions) of SLS. However, when delamination takes place in areas with shear stresses (modes B,ns,s and D,ns,s), the unfavourable effect of the non symmetric delamination is also observed for SLS (Fig. 4), similarly to what happens for DLS.
Delamination mode A

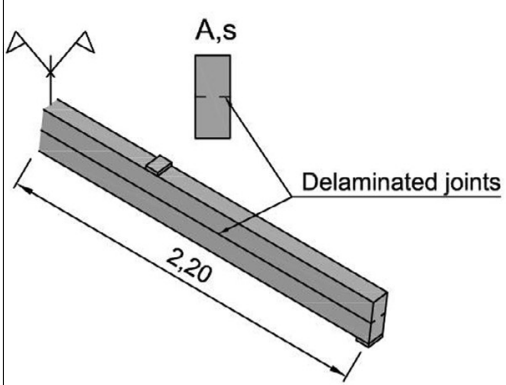

Delamination mode D

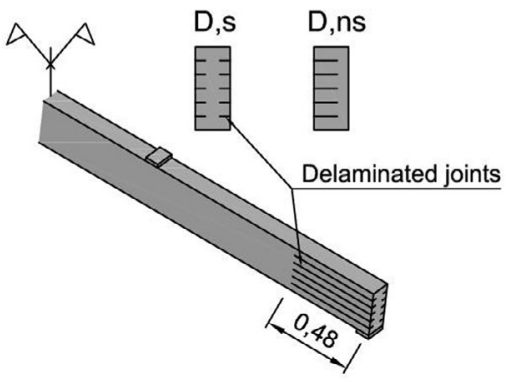

Delamination mode B

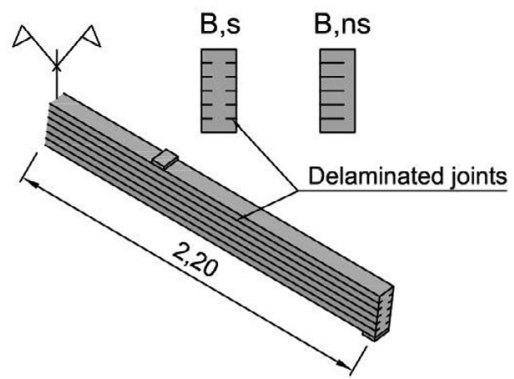

Delamination mode $\mathrm{E}$

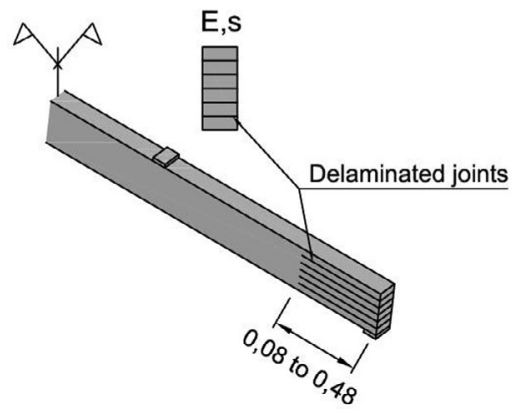

Fig. 2. Delamination modes.
Delamination mode $\mathrm{C}$

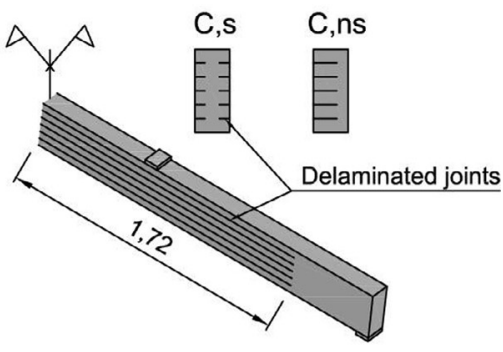<smiles>[X]C([X])[V]</smiles> 
a) DLS - maximum deformation in y direction

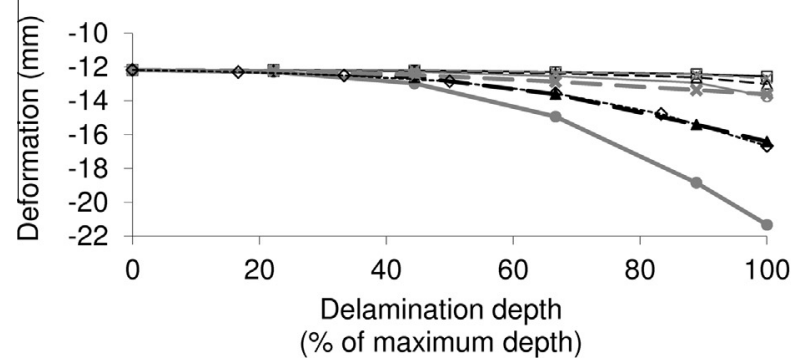

b) DLS - maximum deformation in z direction

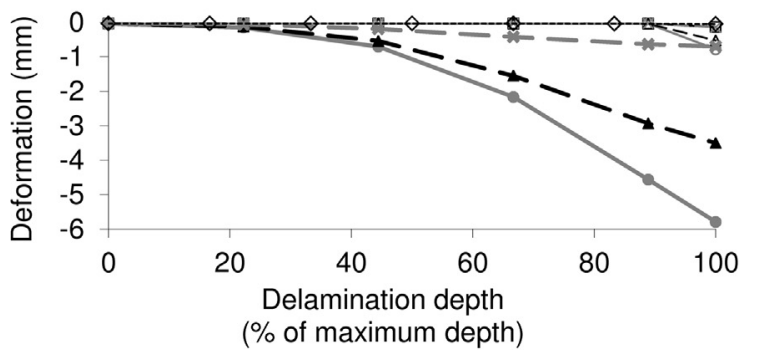

$\longrightarrow B, n s, d \quad-A-C, s, d$

Fig. 3. Variation of maximum deformations for the deformation limit state.

a) SLS - maximum deformation in y direction

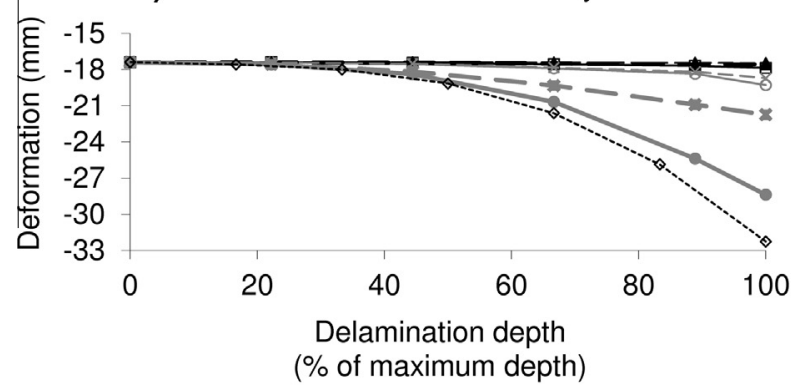

b) SLS - maximum deformation in z direction

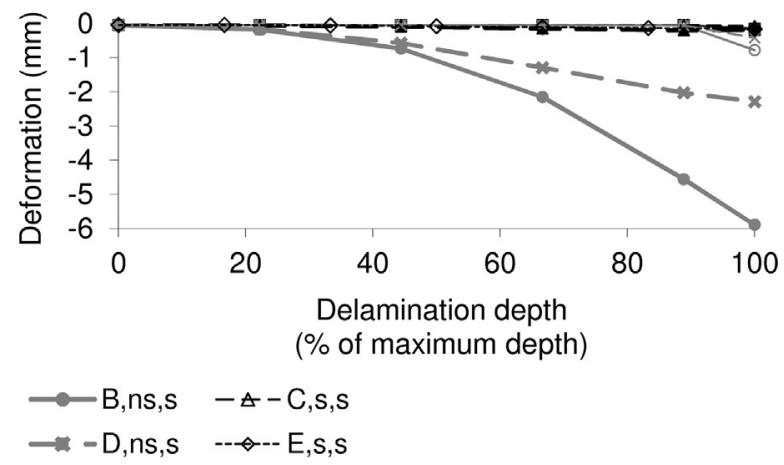

Fig. 4. Variation of maximum deformations for the shear strength limit state.

Lateral instability due to non symmetric delamination, causes an increase of tension stresses in $x$ direction for modes B,ns,d and C,ns,d (Fig. 5a), has happened with deformations. This was particularly observed in the lower fibers, where stresses are higher. For delamination in all length (mode B,ns,d) the increase of stresses is more relevant at loaded areas, whereas for delamination just in the central zone (mode C,ns,d) this increase is also significant at the longitudinal transition between delaminated and non delaminated areas. Compression stresses also increase for these two modes (Fig. 5b) being more relevant at loaded areas. Non symmetric delamination (modes $\mathrm{B}, \mathrm{ns}, \mathrm{d}, \mathrm{C}, \mathrm{ns}, \mathrm{d}$ and $\mathrm{D}, \mathrm{ns}, \mathrm{d}$ ) induces also the increase of shear stresses in the $x-y$ plane relatively to symmetric modes (Fig. 6).

\subsection{Influence of delamination localization}

The increase of stresses is related with the magnitude of bending and shear stresses at delaminated areas. In the case of deformation limit state (as also for the bending limit state), delamination near the beam ends (mode D) produces very small increase of tension and compressive stresses in $x$ direction and deformation (Figs. 3 and $5 \mathrm{a}$ and b), because the delaminated areas do not affect zones with high bending moments. Compared to mode D, delamination mode $\mathrm{E}$ leads to higher deformation in the $y$ direction, higher maximum tension stresses in the $x$ and $y$ directions and higher maximum shear stresses in the $x-y$ plane.

On the contrary, modes B,ns,d and C,ns,d, that include delamination in high bending moment zones, lead to a higher increase of tension and compression stresses in the $x$ direction. However, it should be noted that despite modes B,ns, $\mathrm{d}$ and C,ns, $\mathrm{d}$ are very serious situations for the higher delamination depths, the maximum tension stresses in the $x$ direction are not higher than the design stress.

The increase of stresses is in some cases related with delamination located at high shear stress areas. This is the reason why mode D,ns,d has a higher increase of shear stresses in the $x-y$ plane as compared to mode $\mathrm{C}, \mathrm{ns}, \mathrm{d}$, because in the first mode delamination is only located near the supports (Fig. 6), where the shear stress exceeds the design value. However, compression stresses in the $y$ direction are not always higher for modes with delamination near the supports. Mode E,s,d has high delamination near the supports, although its compression stresses do not increase with delamination depth (Fig. 5d). This fact is related with the uniform contact of the lamellas along the beam width, at the support areas, that leads to uniform compression stresses without stress concentration. Modes $C$ do not increase compression stresses because of the absence of delamination near the supports. Mode A,s,d has only delamination on the middle joint, introducing low perturbation on stress distribution that leads to very low increase on compression stresses in the $y$ direction. On the other hand, modes B and D which have non uniform contact between the lamellas at the support zones, lead to an increase of the compression and tension stresses (Fig. 5c and d). This fact highlights the unfavourable effect of delamination at the supports.

For all symmetric delamination modes (A,s,d, B,s,d, C,s,d and D, $\mathrm{s}, \mathrm{d})$ the increase of shear stresses in the $x-y$ plane with the delamination depth is similar, because delamination covers the lateral third (totally or partially) of the beam for all these modes 
a) DLS - maximum tension stresses in $x$ direction

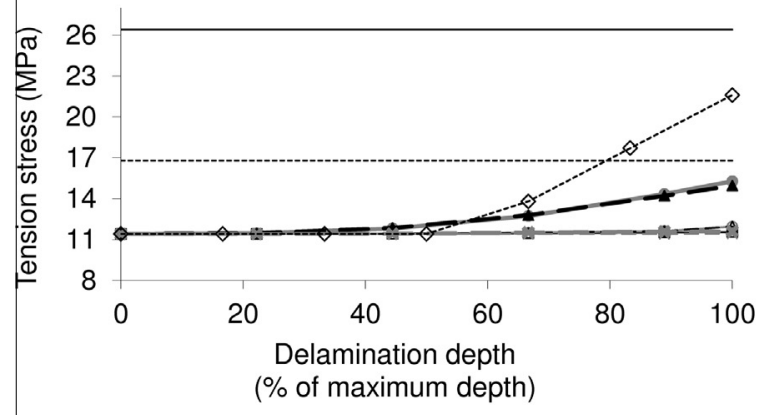

c) DLS - maximum tension stresses in y direction

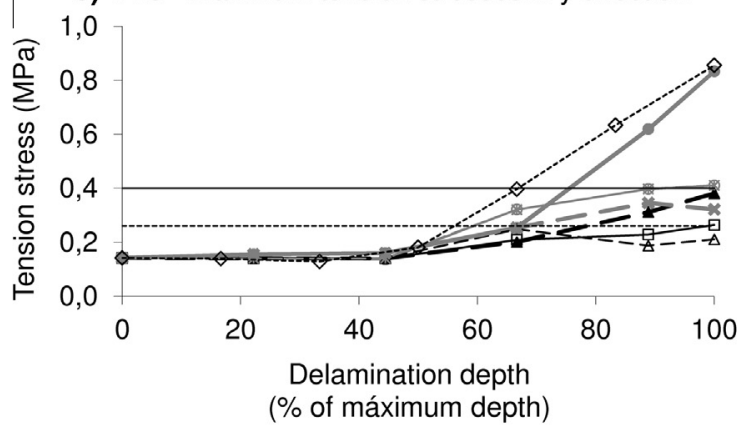

(\% of máximum depth) b) DLS - maximum compression stresses in $x$ direction

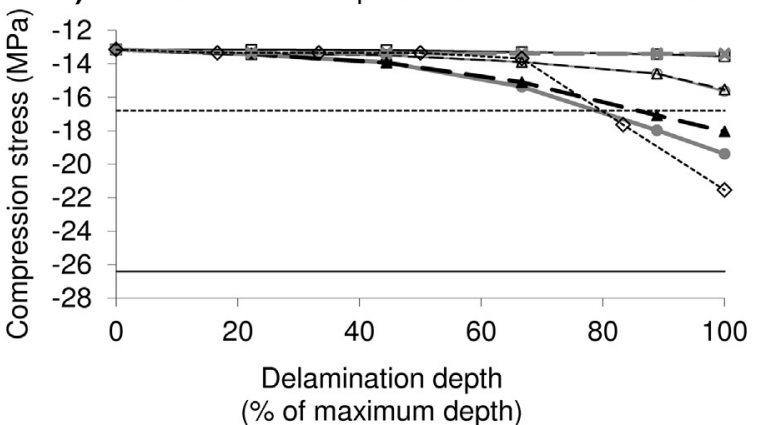

(\% of maximum depth)

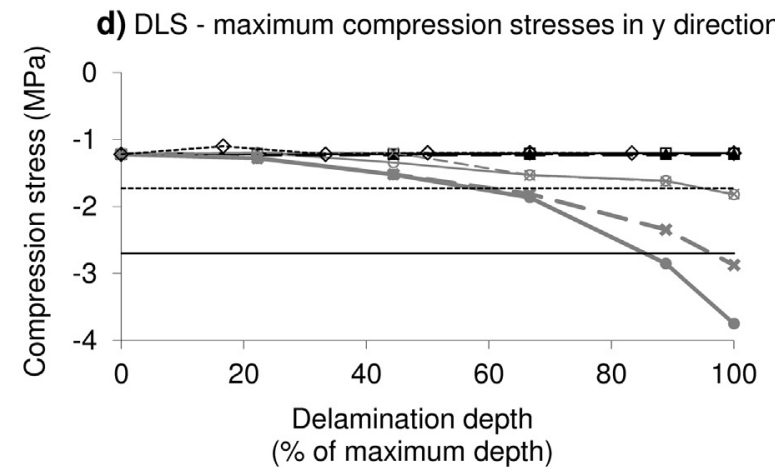

(\% of maximum depth)

$\rightarrow-C, n s, d \quad-*-D, s, d \quad \longrightarrow-D, n s, d \quad-\cdots-E, s, d$

------- Design stress (EC 5) _ C Characteristic stress

Fig. 5. Variation of maximum tension and compression stresses for the deformation limit state

\section{DLS - maximum shear stresses in $x-y$ plane}

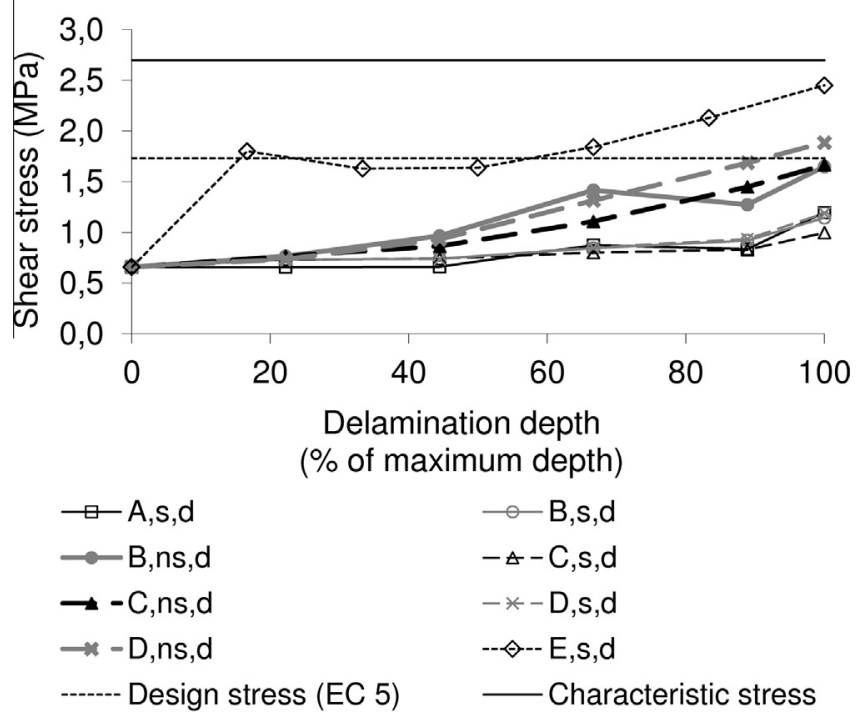

Fig. 6. Variation of maximum shear stresses for the deformation limit state.

(Fig. 6). In these cases the shear stresses increase mainly along the transversal transition between the glued and delaminated joint.

For the shear strength limit state, the stiffness reduction, due to delamination, in areas of higher bending and shear stresses, implied higher deformation in the $y$ direction for mode $\mathrm{E}, \mathrm{s}, \mathrm{S}$ than for other modes (Fig. 4a). Deformations in the $y$ direction are higher for mode B,ns,s than for D,ns,s which is a consequence of

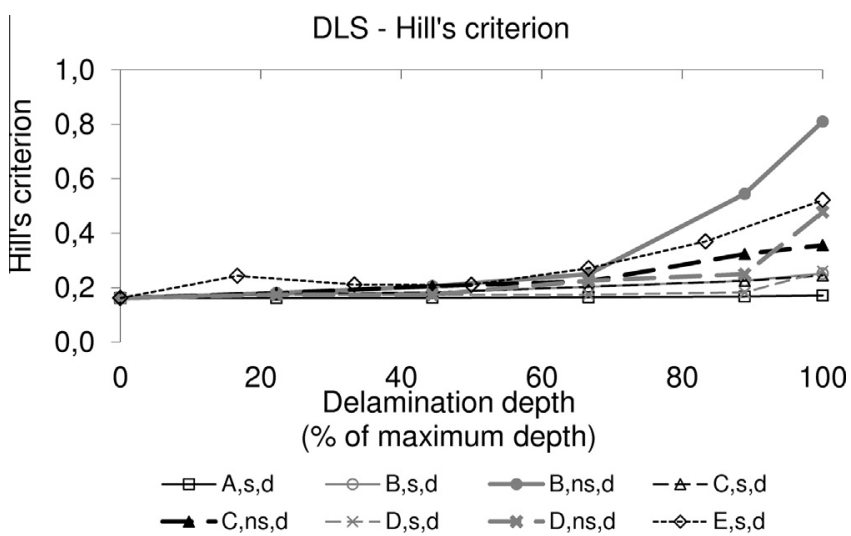

Fig. 7. Variation of Hill's criterion for the deformation limit state.

the higher delamination of mode B,ns,s. However, deformation for mode C,ns,s (delamination in the central zone) is almost negligible despite the total length of delamination is higher than for mode D,ns,s, which, on the other hand, has delaminated areas near beam ends, where high shear stresses occur. This evidence shows the unfavourable effect of delamination on high shear stresses areas. In addition, mode D,ns,s has higher tension stresses on the $x$ direction than for mode B,ns,s, as also happens for modes D,s,S and $\mathrm{B}, \mathrm{s}, \mathrm{S}$, reaffirming the importance of this phenomenon.

\subsection{Influence of delamination depth}

Regarding the situations with symmetric delamination, it is observed that for mode E,s,d the increase of deformation in the $y$ 


\section{BLS - Hill's criterion}

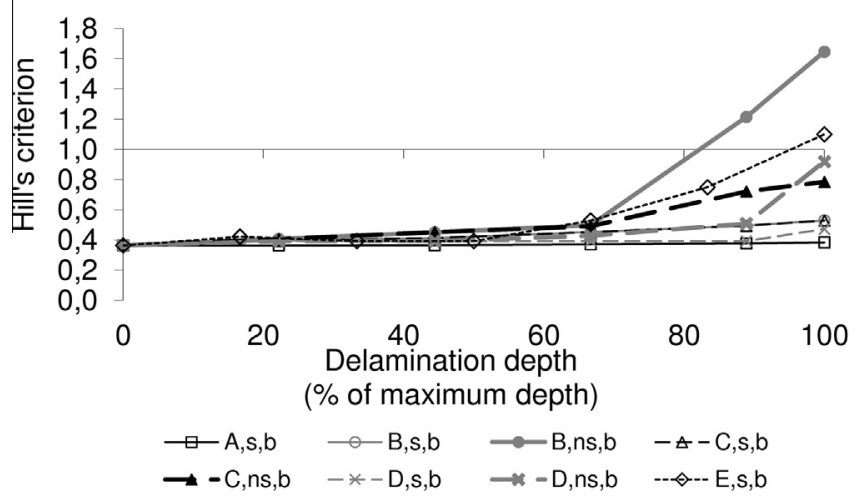

Fig. 8. Variation of Hill's criterion for the bending limit state.

direction with the delamination depth is higher than for the remaining symmetric modes, where the increase of deformation is very low (Fig. 3a). For mode E,s,d the delamination affects the whole beam width, giving a significant reduction of stiffness on the delaminated zone, leading to high deformations, while for the remaining modes the stiffness is not significantly changed, leading to a lower increase of deformation. In addition, for delamination mode E,s,d, the distribution of stresses in the $x$ direction (Fig. 5a and b) showed a concentration in the longitudinal transition between delaminated and non delaminated areas, leading to a significant increase of stresses with the delamination depth. The delamination of the beam ends, affecting the whole beam width, causes the lamellas to perform individually. Each lamella behaves similarly to a cantilever, with one fixed end in the transition zone, where maximum tension and compression stresses are obtained.

The increase of stresses with the delamination depth for mode E,s,d achieves higher values than the other delamination modes (Figs. 5 and 6). For the most unfavorable situation, mode E,s,d constitutes a comparable delamination situation to modes D,s,d and D, $\mathrm{ns}$, d, since, for the maximum delamination depth, both modes have $480 \mathrm{~mm}$ of delamination from the ends, differing only because modes D keep $10 \mathrm{~mm}$ of glued joint along the $480 \mathrm{~mm}$ length. However, for modes $\mathrm{D}$, the increase of tension stresses in the $x$ direction (Fig. 5a) is very low, indicating that delamination affecting the whole beam width is very unfavorable.

For shear strength limit state the more unfavourable effect of mode E,s,S is also observed (Fig. 4) as for DLS and BLS.

\subsection{Stress states}

Hill's criterion was used to find out the most unfavorable stress states and to see in which situations they can approach to the elastic limit.

None of the modes simulated for the DLS exceeded the Hill's criterion (Fig. 7). For the BLS the unit is exceeded for delamination B, ns,b between 80 and $90 \mathrm{~mm}$ deep and for delamination E,s,b close to $480 \mathrm{~mm}$ deep (Fig. 8). Note that these delamination situations are in practice very rare since they would be in principle prevented by the usually recommended periodic inspection. It is also observed that the Hill's criterion increases very slowly with delamination till this reaches $60 \%$ of the beam width, and very quickly after that value, what can be an important indication for the inspection of structures in service.

For the shear strength limit state, delamination is in general more unfavourable (always $\geqslant 1$ ) than for the other two limit states (Fig. 9). For the reference situation, the Hill's criterion is particularly critical for modes B,ns, D,ns and E. However, for mode A,s,s
SLS - Hill's criterion

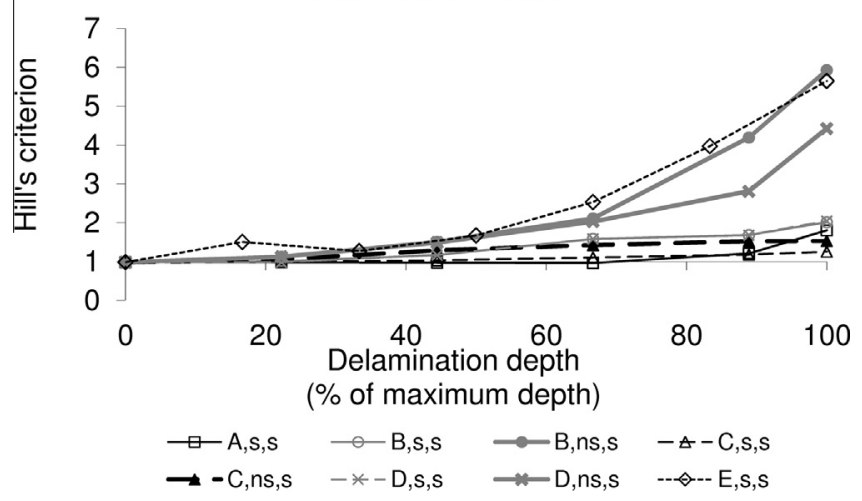

Fig. 9. Variation of Hill's criterion for the shear strength limit state.

there is no increase of Hill's criterion at the support zones, being more relevant at the middle joint. For modes $C$ the critical zone is at the load areas without relevant increase at the support zones. For mode E the zone where the Hill's criterion assumes higher values is at the longitudinal transition between glued and delaminated joints. The most unfavourable modes are non symmetric delamination, especially when affecting the ends of the beams and all glue lines.

\subsection{Comparison with experimental data}

In order to validate the model for delaminated beams, the results obtained by Silva et al. [34] were compared with the numerical simulations done in this work. Silva et al. [34] carried out an experimental work using straight beams $0.095 \mathrm{~m}$ wide $\times 0.175 \mathrm{~m}$ high (5 lamellas) $\times 3.09 \mathrm{~m}$ long, simply supported over a $2.92 \mathrm{~m}$ span. The test setup was according to EN 408, with the span equal to 18 times the beam height, and two loads symmetrically applied relatively to the middle of the beam, as was also considered in the numerical modeling, and so with comparable structural performance. The beams were manufactured with intentionally delaminated areas, following some delamination geometries used in this work, corresponding to mode B with 66\% delamination depth and to mode E with $100 \%$ delamination depth.

The referred experimental results showed that the bending stresses and modulus of elasticity for mode B (66\% delamination depth) were similar to those of the reference beams (with no delamination). This is compatible with predictions given in Figs. $3 a$ and 5 a for delamination depth equal to $66 \%$.

Regarding mode E with $100 \%$ delamination “depth", the predicted stress (21.6 MPa - Fig. 5a) is about double the predicted stress for $0 \%$ delamination (11.4 MPa - Fig. 5a), and the modulus of elasticity, determined using the deformation $(16.7 \mathrm{~mm}$ Fig. 3a), the load and geometrical properties referred above, is $64 \%$ of the reference modulus of elasticity $(11,600 \mathrm{MPa})$. These are also in line with the corresponding average tests results obtained by Silva et al. [34] for beams corresponding to mode E ( $100 \%$ delamination "depth"), being $47 \%$ of the bending strength and $65 \%$ of the elastic modulus of uncracked beams.

Thus, the experimental bending stresses and modulus of elasticity for both delamination modes seem to confirm the developed numerical model, being in line with the stresses and deformations found in this work.

\section{Conclusions}

A study was conducted to evaluate the influence of the delamination magnitude and location on the mechanical performance of 
straight glued laminated beams, using a finite element model, in order to address the problems that the separation of bonded lamellas can create in glued laminated timber structures.

Results indicate that when delamination is non-symmetric regarding the beam cross section, it can cause the member's lateral instability, thus increasing its stresses and deformation. Additionally, delamination around supports or under loading application points may rise highly unfavourable stresses in the beam, especially under high shear stresses where the glulam failure is more likely to occur. Delamination is particularly critical when it goes through all the width of the beam.

On the contrary, delamination is not a problem when it occurs in members or member areas with low shear stresses, particularly when it is symmetric and does not go through the whole width of the beam.

The stresses corresponding to the bending or deformation limitstate may reach the elastic limit only for very important delamination. Nevertheless, delamination depth higher than $60 \%$ of the cross section width may be regarded as a turn point beyond which the structural integrity may be at risk.

It should be noted that the performed analysis relates to straight beams, where tension stresses perpendicular to the grain are not relevant.

\section{Acknowledgments}

The authors wish to thank Fundação para a Ciência e a Tecnologia (Portuguese Foundation for Science and Technology), for the PhD grant (number SFRH/BD/30310/2006) given to Florindo Gaspar.

\section{References}

[1] G.M. Raftery, A.M. Harte, P.D. Rodd, Bond quality at the FRP-wood interface using wood-laminating adhesives, Int. J. Adhes. Adhes, 29 (2009) 101-110.

[2] F. Gaspar, Estruturas de madeira lamelada-colada - viabilidade da utilização da madeira de pinho bravo tratada com produto preservador (M.Sc. thesis), Technical University of Lisbon, 2006.

[3] B.H. River, Fracture of adhesive-bonded wood joints, in: A. Pizzi, K.L. Mittal (Eds.), Handbook of Adhesive Technology, Marcel Dekker, New York, 1994 Chapter 9.

[4] E. Serrano, P.J. Gustafsson, Influence of bondline brittleness and defects on the strength of timber finger-joints, Int. J. Adhes. Adhes. 19 (1999) 9-17.

[5] H. Wernersson, Fracture characterization of wood adhesive joints (Doctoral thesis), Report TVSM-1006, Division of Structural Mechanics, Lund University, Sweden, 1994.

[6] P.J. Gustafsson, Tests and test results on mechanical properties of adhesive bond lines, in: C.J. Johansson, T. Pizzi, M.V. Leemput (Eds.), Wood Adhesion and Glued Products, Cost Action E13 - WG 2, 2001; pp. 7-24.

[7] E. Serrano, H.J. Larsen, Numerical investigations of the laminating effect in laminated beams, J. Struct. Eng. 125 (7) (1999) 740-745.

[8] S. Aicher, Structural adhesive joints including glued-in bolts, in: S. Thelandersson, H.J. Larsen (Eds.), Timber Engineering, John Wiley and Sons Ltd, 2003, pp. 333-364.

[9] H. Petersson, Fracture design criteria for wood in tension and shear, in: Pacific Timber Engineering Conference, Queensland, Australia, 1994.

[10] E. Serrano, P.J. Gustafsson, H.J. Larsen, Modeling of finger-joint failure in gluedlaminated timber beams, J. Struct. Eng. 127 (8) (2001) 914-921.
[11] L.A. Soltis, T.D. Gerhardt, Shear design of wood beams: State of the art, Forest Products Laboratory, Department of Agriculture, Forest Service, Madison, WI, U.S., 1988.

[12] S.R. Khorasan, Finite-element simulations of glulam beams with natural cracks (M.Sc. thesis), Department Mechanical Engineering, Blekinge Institute of Technilogy, Karlskrona, Sweden, 2012.

[13] D. Anderson, J. Oden, Träs skjuvhållfasthet och limträbalkars tvärkraftskapacitet - Provningar och beräkningar (M.Sc. thesis), Dep Construction Sciences, Structural Mechanics, Lund University, 2009.

[14] A. Pousette, M. Ekevad, Shear resistance of glulam beams with cracks, CIBW18/45-12-5, Sweden, 2012.

[15] S. Berg, D. Sandberg, M. Ekevad, M. Vaziri, Crack influence on load-bearing capacity of glued laminated timber using extended finite element modelling. Wood Material Science \& Engineering, 2015 (accepted 12 February 2015).

[16] EN 1995-1-1 Eurocode 5, Design of Timber Structures - Part 1-1: General Common Rules and Rules for Buildings, Brussels, European Committee for Standardization, 2004.

[17] EN 1194 Timber structures, Glued laminated timber, Strength classes and determination of characteristic values, Brussels, European Committee for Standardization, 2002

[18] EN 408 Timber structures, Structural timber and glued laminated timber, Determination of some physical and mechanical properties, Brussels, European Committee for Standardization, 2003.

[19] J. Bodig, B. Jayne, Mechanics of Wood and Wood Composites, Krieger Publishing Company, Florida, 1993.

[20] R.F.S. Hearmon, The elasticity of wood and plywood, Special Report 7, Forest Products Research, Department of Science and Industry Research, London, 1948.

[21] J.C. Xavier, N.M. Garrido, M. Oliveira, J.L. Morais, P.P. Camanho, F. Pierron, A comparison between the Iosipescu and off-axis shear test methods for the characterization of Pinus pinaster Ait, Composites 35A (2004) 827-840.

[22] B. River, Method for evaluating nonrigid adhesives for use in structural joints, J. Appl. Polym. Sci. 40 (1984) 235-250.

[23] J. Bomba, P. Šedivka, M. Böhm, M. Devera, Influence of moisture content on the bond strength and water resistance of bonded wood joints, BioResources 9 (3) (2014) 5208-5218

[24] B. Källander, M. Kemmsies, C.J. Johansson, ASTM D 4680.92 - Standard Test Method for Creep and Time-to-Failure of Adhesives in Static Shear by Compression Loading - Experiences Using the Method on 3 Adhesives, Final Draft Report, SP Swedish National Testing and Research Institute, Sweden, 2000.

[25] R. Hill, The Mathematical Theory of Plasticity, Clarendon Press, Oxford, 1950.

[26] O. Hoffman, The brittle strength of ortotropic materials, J. Compos. Mater. 1 (2) (1967) 200-206.

[27] S.W. Tsai, E.M. Wu, A general theory of strength for anisotropic materials, J. Compos. Mater. 5 (1) (1971) 58-80.

[28] S.C. Cowin, On the strength anisotropy of bone and wood, J. Appl. Mech. 46 (1979) 832-838.

[29] M.H. Yu, Unified Strength Theory and Its Applications, Springer-Verlag, Berlin Heidelberg GmbH, 2004.

[30] N.T. Mascia, R.A. Simoni, Analysis of failure criteria applied to wood, Eng. Fail. Anal. 35 (2013) 703-712

[31] J.M. Cabrero, C. Blanco, K.G. Gebremedhin, A.M. Meizoso, Assessment of phenomenological failure criteria for wood, Eur. J. Wood Prod. 70 (6) (2012) 871-882.

[32] B. Kasal, R.J. Leichti, State of the art in multiaxial phenomenological failure criteria for wood members, Prog. Struct. Eng. Mater. 7 (2005) 3-13.

[33] P. Guindos, M. Guaita, The phenomenological fracture criteria and the stress integration volumes in heterogeneous models of wood, in: P. Quenneville (Eds.), World Conference on Timber Engineering, New Zealand, 2012, vol. 5, pp. 629-633.

[34] R. Silva, H. Cruz, J.G. Ferreira, Reparação de vigas de madeira lamelada colada com delaminação através de parafusos auto perfurantes, in: 5as Jornadas Portuguesas de Engenharia de Estruturas, Laboratório Nacional de Engenharia Civil, Lisbon, 2014 